\title{
To evaluate the Gender Differences in Learning Style Modalities among the Undergraduate Students and their Preferred Mode of Learning
}

\author{
${ }^{1}$ Aparna Garg, ${ }^{2}$ Manisha Sankhla, ${ }^{3}$ RC Gupta
}

\begin{abstract}
Background: Academic demands of medical students are quite high. Learning styles may be classified into four major sensory modalities-visual, auditory, read-write and kinesthetic, that one most prefers to use when internalizing information.
\end{abstract}

Objectives: The purpose of the study was to evaluate the gender differences in learning style modalities among the First Year Undergraduate Students and their Preferred Mode of Learning.

Methodology: Total 243 first year students of various medical courses (135 MBBS, 56 BDS, and 52 BPT) attending lectures in the Department of Physiology, Mahatma Gandhi Medical College and Hospital, Jaipur, Rajasthan were included for the project. Learning style preference was identified using the visual, auditory, read-write and kinesthetic (VARK) online inventory developed by Fleming, 1992. A questionnaire was filled by the students which included their demographic profile, medical science stream and preferred sensory modality of instruction.

Findings: Learning style of the students of various medical courses showed a statistically significant difference according to VARK questionnaire $(p<0.0001)$. Within the group, based on VARK, the preferred Sensory Modality was kinesthetic in MBBS, BDS and BPT students. On the basis Preferred Sensory Mode, kinesthetic was the preferred mode in MBBS, BDS and visual mode amongst BPT students. The most common pattern of learning was bimodal in male and female students of the various medical courses.

Conclusion: Present findings suggest that kinesthetic was the preferred learning style by both individual preferred sensory modality and VARK inventory tool, and was found to be statistically significant among the students of medical and allied sciences. The gender differences when evaluated for both the individual preferred sensory modality and VARK inventory tool, it was found to have a predilection for the kinesthetic mode in both the male as well as female students.

Keywords: Auditory, Kinesthetic, Learning modes, Learning style preferences, Visual, Read-write.

${ }^{1}$ Associate Professor, ${ }^{2}$ Senior Demonstrator, ${ }^{3}$ Professor and Head

1,3 Department of Physiology, Mahatma Gandhi Medical College and Hospital, Jaipur, Rajasthan, India

${ }^{2}$ Department of Physiology, Sawai ManSingh Medical College Jaipur, Rajasthan, India

Corresponding Author: Aparna Garg, Associate Professor Department of Physiology, Mahatma Gandhi Medical College and Hospital, Jaipur, Rajasthan, India, Phone: +91 8504092472 e-mail: draparnagarg19@gmail.com
How to cite this article: Garg A, Sankhla M, Gupta RC. To evaluate the Gender Differences in Learning Style Modalities among the Undergraduate Students and their Preferred Mode of Learning. J Mahatma Gandhi Univ Med Sci Tech 2016;1(2):58-63.

Source of support: Nil

Conflict of interest: None

\section{CURRICULUM INNOVATION PROJECT}

\section{Background}

Academic demands of health science students are very rigorous since medical education involves a large volume of content and different ways of delivery of information and knowledge. Today's medical students are quite heterogeneous in terms of age, experience, culture, ethnicity, educational backgrounds and level of preparedness as well as learning preferences. ${ }^{1}$

Educational researchers have reported that each individual has a specific learning style and if the method of information delivery conforms to their learning style, learning is more effective. ${ }^{2}$ Learning styles can be defined in terms of sensory modality in which a student prefers to take new information maybe in the form of the following sensory modalities. That is visual, aural, read/write, and kinesthetic (VARK). ${ }^{3}$ Learning style preferences are the manner in which, and the conditions under which, learners most efficiently and effectively perceive, process, store and recall what they are attempting to learn. ${ }^{4}$

Fleming VARK inventory tool is the most widely accepted and used for assessing individual preferences for learning with sensory modalities. VARK is an acronym that stands for four sensory modes of learning: Visual (V), Aural (A), Read/Write (R) and Kinesthetic (K), depending on the neural system with which a learner prefers to receive information. ${ }^{5}$

Students with visual preference learn best by seeing or observing diagrams, pictures, graphs, and flowcharts. Auditory learners gather information best by hearing or recording lectures, enjoy discussions and tutorials. Read/ Write learners prefer printed material to gain knowledge. Kinesthetic learners learn by using physical experience: Touching, performing an activity, moving, lessons that emphasize doing, and manipulation of objects. ${ }^{6}$ 
Physiology is a subject, i.e., complex and difficult for many students to internalize. It is therefore important for physiology instructors to take extra steps to make sure that they are effectively communicating the information to their students. ${ }^{7}$ Physiology is an integral part and an important aspect of the medical curriculum, most of the understanding for the entire medical sciences is based on the understanding of this subject.

According to the pertinent scientific literature one particularly effective way to enhance the communication of material to students is for instructors to incorporate multiple learning styles into their lecture presentations. Instructors that use multiple learning styles are more likely to present information in the particular style that is preferred by each student; thus, student learning is enhanced.?

In that sense, an instructor's most important responsibility and challenge is to present information through a variety of teaching methods since teaching and student learning styles may affect student academic success. $^{1}$

Disparity between learning and delivery of instruction may lead to frustration in students. This can be reduced by knowing the students learning style preferences which will aide in the development of the most effective teaching approaches so as to improve student learning, retention and motivation. ${ }^{8}$

Moreover, it has been reported that males have a preference for rational evaluation and logic, whereas females use "elaborative" processing in which they tend to seek personal relevance or individual connections with the material being taught..$^{9}$ Search of literature also supports a gender-based preference in learning style in which males and females are unique. ${ }^{1,7,8}$

Therefore, the present study was designed to evaluate preferred learning sensory modality and to assess whether there exists any gender difference in the learning style preferences or not among medical and allied science students.

\section{AIMS AND OBJECTIVES}

To evaluate gender differences in learning style modalities among the first year undergraduate students of medical and allied sciences and to know their preferred mode of learning.

\section{Objectives}

- To evaluate the preferred learning style sensory modality among the first year students of medical and allied sciences using VARK questionnaire.

- To evaluate whether the learning style modality has a predisposition towards gender.

\section{METHODOLOGY}

The curriculum project was conducted in the Department of Physiology at Mahatma Gandhi Medical College and Hospital, Jaipur, after obtaining the clearance from the Institutional Ethical Committee.

Sample design: A cross sectional study.

Sample size and study group: Total of 243 (104 males, 139 females) undergraduate students of the first year from medical, dental sciences, and physiotherapy who attended lectures in the Department of Physiology.

Study period: November 2015 to February 2016.

Study area: Department of Physiology, Mahatma Gandhi Medical College and Hospital, Jaipur.

The faculty and the students were sensitized toward the VARK questionnaire ${ }^{10}$ with the help of an orientation class and an informed consent of all the participating students was taken.

For the purpose of the above study, the following information was taken into consideration:

- A questionnaire was formulated, where the students were asked to furnish the details which include: age, sex, study course, language preferred and their preferred sensory modality of instruction, i.e.:

- Visual (looking at and making pictures, animations, graphs, tables, etc.)

- Auditory (listening to and participating in speeches, discussions, and question and answer sessions)

- Read/write (reading and writing text associated with the textbook, class notes, etc.), or

- Kinesthetic (engaging in hands on experiences, manipulating objects, etc.).

- The fleming VARK inventory tool (7.8 version) was distributed to all the participants of the study. This questionnaire comprises of 16 questions.

- Questionnaire was evaluated on the basis of previously validated scoring instructions mentioned on the VARK questionnaire.

\section{Inclusion Criteria}

- 1st year undergraduate students from medical, dental sciences, and physiotherapy.

- Willingness to participate in the study.

\section{Exclusion Criteria}

- Nursing students

- Incompletely filled questionnaire.

\section{OBSERVATION TABLES AND RESULTS}

Total 243 students of various medical courses completed the questionnaire (135 MBBS, $56 \mathrm{BDS}$, and $52 \mathrm{BPT}$ ), were 
Table 1: Individual preferred sensory modality preferences (based on questionnaire 1)

\begin{tabular}{|c|c|c|c|c|c|c|c|c|c|c|}
\hline \multirow{2}{*}{$\begin{array}{l}\text { Medical courses } \\
\text { (no. of students) }\end{array}$} & \multicolumn{2}{|c|}{ V } & \multicolumn{2}{|c|}{$A$} & \multicolumn{2}{|c|}{$R$} & \multicolumn{2}{|c|}{$K$} & \multirow[b]{2}{*}{$X^{2}(d f)$} & \multirow[b]{2}{*}{$p$-value } \\
\hline & $N$ & $\%$ & $N$ & $\%$ & $N$ & $\%$ & $N$ & $\%$ & & \\
\hline $\begin{array}{l}\text { MBBS } \\
(135)\end{array}$ & 36 & 26.66 & 25 & 17.70 & 32 & 26.66 & 42 & 31.11 & & \\
\hline $\begin{array}{l}\text { BDS } \\
(56)\end{array}$ & 14 & 25.00 & 20 & 35.71 & 10 & 17.8 & 12 & 21.42 & $8.92(6)$ & $\begin{array}{l}0.178 \\
\text { NS }\end{array}$ \\
\hline $\begin{array}{l}\text { BPT } \\
(52)\end{array}$ & 17 & 32.69 & 9 & 17.30 & 13 & 25 & 13 & 25 & & \\
\hline $\begin{array}{l}\text { Total } \\
(243) \\
\end{array}$ & 67 & & 54 & & 55 & & 67 & & & \\
\hline
\end{tabular}

NS:Non-significant

Table 2: VARK sensory modality preferences

\begin{tabular}{|c|c|c|c|c|c|c|c|c|c|c|}
\hline \multirow[b]{2}{*}{ Medical courses } & \multicolumn{2}{|c|}{ V } & \multicolumn{2}{|c|}{$A$} & \multicolumn{2}{|c|}{$R$} & \multicolumn{2}{|c|}{$K$} & \multirow[b]{2}{*}{$X^{2}(d f)$} & \multirow[b]{2}{*}{$p$-value } \\
\hline & $N$ & $\%$ & $N$ & $\%$ & $N$ & $\%$ & $N$ & $\%$ & & \\
\hline $\begin{array}{c}\text { MBBS } \\
(135)\end{array}$ & 7 & 5.185 & 40 & 29.62 & 16 & 11.85 & 72 & 53.33 & & \\
\hline $\begin{array}{l}\text { BDS } \\
(56)\end{array}$ & 7 & 12.5 & 15 & 26.78 & 12 & 21.4 & 22 & 39.28 & $16.7(6)$ & $\begin{array}{c}0.011 \\
S\end{array}$ \\
\hline $\begin{array}{l}\text { BPT } \\
(52)\end{array}$ & 6 & 11.53 & 4 & 7.69 & 10 & 19.2 & 32 & 61.53 & & \\
\hline $\begin{array}{l}\text { Total } \\
(243)\end{array}$ & 20 & & 59 & & 38 & & 126 & & & \\
\hline
\end{tabular}

S: Significant

Table 3: Individual preferred learning style modes in male and female students

\begin{tabular}{lcccc}
\hline & \multicolumn{2}{c}{ Male } & \multicolumn{2}{c}{ Female } \\
\hline Mode of & $($ MBBS+BDS+BPT) 104 & \multicolumn{3}{c}{ (MBBS+BDS + BPT) 139 } \\
\cline { 2 - 5 } $\begin{array}{c}\text { learning } \\
\text { style }\end{array}$ & $\begin{array}{c}\text { No. of } \\
\text { students }\end{array}$ & $\%$ & $\begin{array}{c}\text { No. of } \\
\text { students }\end{array}$ & $\%$ \\
\hline $\mathrm{V}$ & 29 & 27.89 & 30 & 21.5 \\
$\mathrm{~A}$ & 14 & 13.48 & 26 & 18.7 \\
$\mathrm{R}$ & 20 & 19.20 & 36 & 25.88 \\
$\mathrm{~K}$ & 41 & 39.42 & 49 & 35.25 \\
\hline
\end{tabular}

Table 5: Different learning style modes in all male and Female students

\begin{tabular}{lcccc}
\hline & \multicolumn{2}{c}{ Male } & \multicolumn{2}{c}{ Female } \\
\hline Mode of & Learning & $($ MBBS+BDS+BPT) 104 & (MBBS+BDS+BPT)139 \\
\cline { 2 - 5 } \multicolumn{1}{c}{ style } & $\begin{array}{c}\text { No. of } \\
\text { students }\end{array}$ & $\%$ & $\begin{array}{c}\text { No. of } \\
\text { students }\end{array}$ & $\%$ \\
\hline Unimodal & 29 & 27.88 & 11 & 7.91 \\
Bimodal & 54 & 51.92 & 58 & 41.72 \\
Trimodal & 14 & 13.46 & 46 & 33.09 \\
Quadmodal & 7 & 6.73 & 24 & 17.26 \\
\hline
\end{tabular}

included in the study while 27 students were excluded as they submitted incomplete questionnaire. The number of female students (139) as compared to the number of male students (104) was observed to be more in totality in all the medical courses. The data were analyzed using chi-square $\left(x^{2}\right)$ test and the statistical significance was set at $\mathrm{p}<0.05$.
Table 4: VARK sensory modality preferences in male and female students

\begin{tabular}{lcccc}
\hline & \multicolumn{2}{c}{ Male } & \multicolumn{2}{c}{ Female } \\
\hline Mode of & $(M B B S+B D S+B P T) 104$ & \multicolumn{3}{c}{$($ MBBS+BDS + BPT) 139 } \\
\cline { 2 - 5 } $\begin{array}{c}\text { Learning } \\
\text { style }\end{array}$ & $\begin{array}{c}\text { No. of } \\
\text { students }\end{array}$ & $\%$ & $\begin{array}{c}\text { No. of } \\
\text { students }\end{array}$ & $\%$ \\
\hline $\mathrm{V}$ & 6 & 5.76 & 13 & 9.35 \\
$\mathrm{~A}$ & 30 & 28.86 & 44 & 31.65 \\
$\mathrm{R}$ & 12 & 11.53 & 14 & 10.07 \\
$\mathrm{~K}$ & 56 & 53.84 & 70 & 50.35 \\
\hline
\end{tabular}

Table 1 showing, individual preferred sensory modality which is statistically nonsignificant $(p<0.178)$ among students of various medical courses. The bold numbers indicate the preferred sensory modality in different courses.

Table 2 showing VARK inventory tool sensory modality preferences, which is statistically significant $(p<0.011)$ among students of various medical courses.

Kinesthetic was the most preferred sensory modality (red), and visual was the least preferred (blue).

Tables 3 and 4, Graphs 1 and 2 show the preferred style of learning in the male and female students based on the individual preferred mode and the VARK questionnaire. It was found to be statistically non significant.

Table 5 and Graphs 3 to 5 showing the mode of learning style preferred: Two, three and four modes of information. 


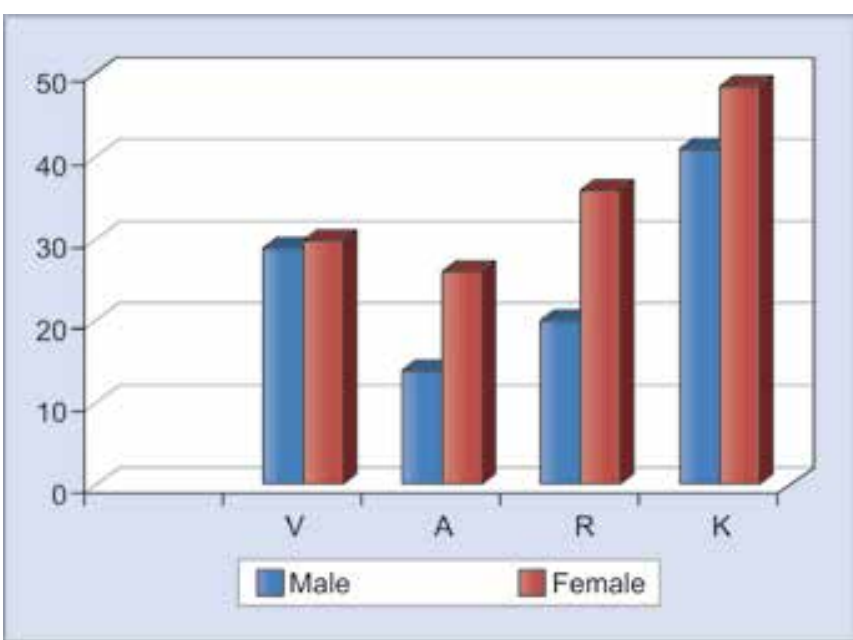

Graph 1: Male and female students' individual preferences for learning style modalities

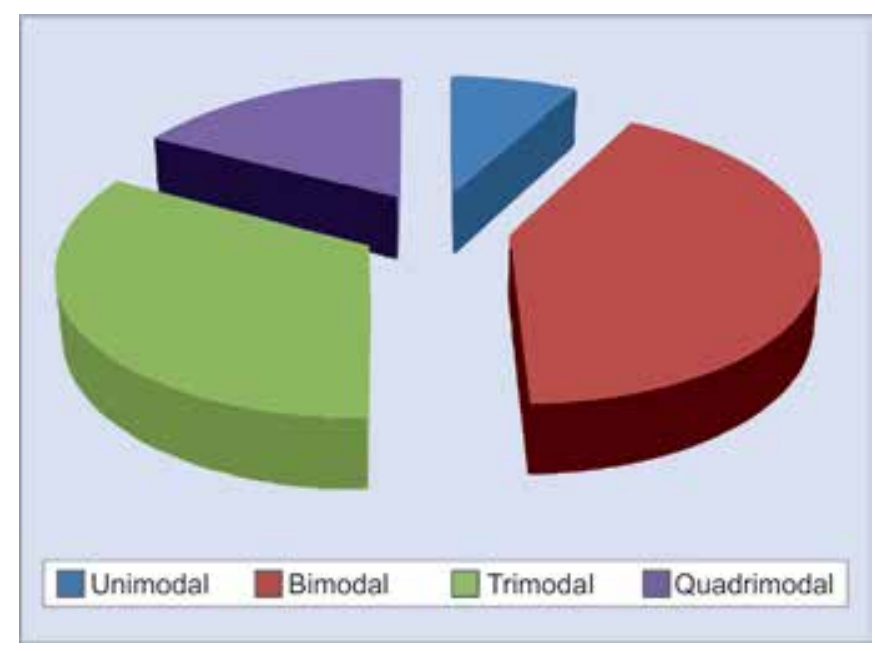

Graph 3: Preferred modalities for female students. Maximum for bimodal and least for unimodal

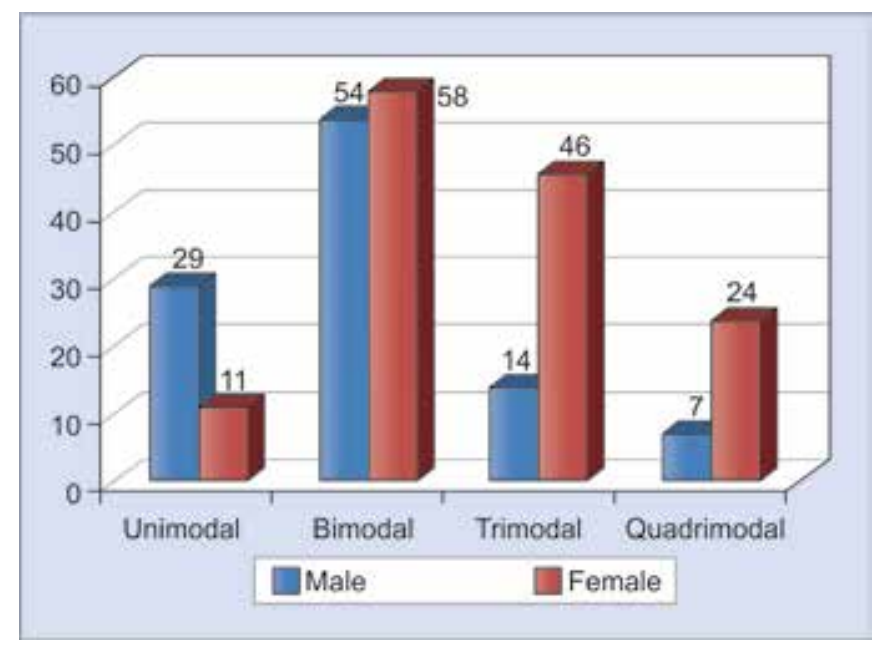

Graph 5: Preferences of male and female students for modes of learning styles

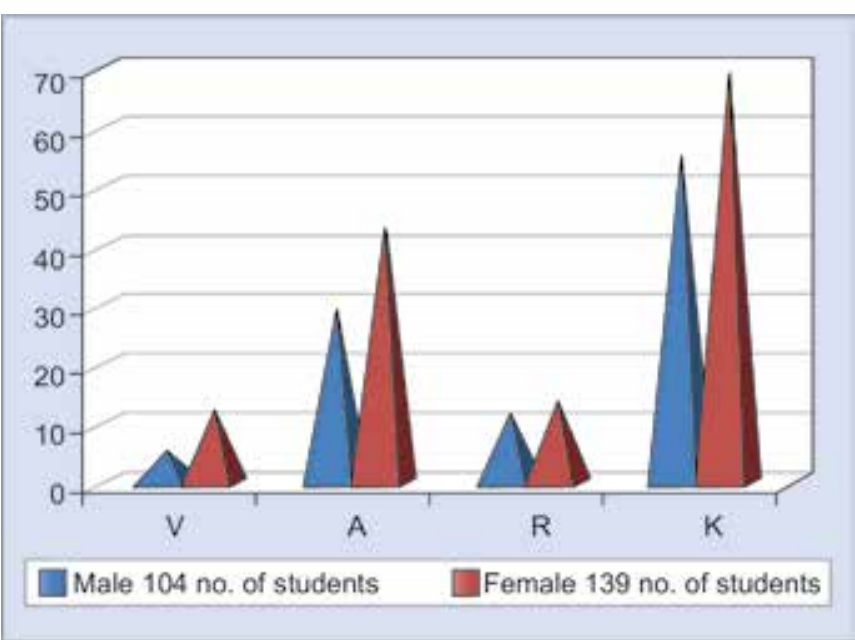

Graph 2: Male and female students' preferences based on VARK questionnaire tool

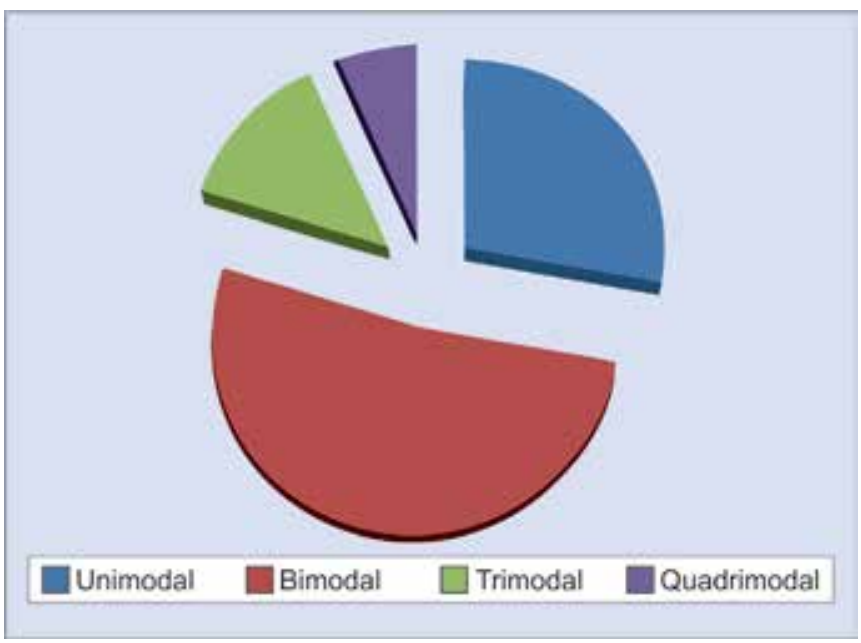

Graph 4: Preferred modalities for female students. Maximum for bimodal and least for the quadrimodal

\section{DISCUSSION}

The learning style as defined by Keefe, is the composite of characteristics cognitive, affective, and physiological characters that serve as relatively stable indicators of how a learner perceives, interacts with and responds to the learning environment. Physiology is a complex and difficult subject for many students who come from a wide variety of cultural and social background. It becomes at times very difficult for the students to imbibe what is being taught.

This study was undertaken with the intention to understand the preferred mode of learning associated with gender differences.

Table 1 shows that individual preferred sensory modality is statistically nonsignificant $(\mathrm{p}<0.178)$ among 
students of various medical courses. Within the course, the MBBS students preferred the kinesthetic sensory mode of learning, auditory was preferred learning style mode in BDS while the BPT students preferred the visual sensory mode of learning.

Table 2 shows VARK sensory modality preferences was statistically significantly $(p<0.011)$ among students of various medical courses. Kinesthetic was the preferred sensory modality for learning by VARK and was significant statistically ( $\mathrm{p}<0.011)$ among the students of medical courses, followed by auditory, read and write. The BPT students though had the kinesthetic preferred VARK sensory modalities their second choice was read and write followed by auditory. The visual sensory modalities were the least preferred modality among the entire medical course through the VARK inventory.

In present study, the preferred sensory modality for the MBBS, BDS and BPT students was the kinesthetic mode. The similar finding by Kumar et $\mathrm{al}^{11}$ reported kinesthetic as the approach for sensory modalities. In contrast to our study report, Jindal et $\mathrm{al}^{12}$ reported for the MBBS student their preference for auditory rather than kinesthetic. However, according to the study done by Lujan and Dicarlo, ${ }^{3}$ the preferred style was read/write. In the MBBS, BDS students the aural mode was the second most preferred modality of which the classical examples is the didactic lectures, except for the BPT students who had the least preference for the aural mode, these students had a better preference for visual mode. In contrast with the present study, Prabha $\mathrm{V}^{13}$ reported that dental students preferred auditory (learning from speech) mode of learning via VARK questionnaire.

The student learners take the information best through practical session, case studies or e-learning (computer modules). As kinesthetic means to learn by hands on approach, it could be provided through clinical rounds, laboratory practical class, cadaver dissection, objective structured clinical examination (OSCE), objective structured practical examination (OSPE), one minute preceptorship (OMP), etc.

The gender is another factor that has been found to influence the student learning. Although it is known that students have a variety of learning style preferences, it is unknown if gender differences in learning style preferences exists among undergraduate physiology students. $^{8}$

In the Tables 3 and 4 , it is seen that there is a statistical nonsignificant relationship between the male/female students for the individual preferred and VARK based sensory modality. When compared individually within the groups, there was an preponderance for kinesthetic [41 males (39.42\%), and 49 females (35.25\%)] followed by visual in the individual preferred sensory modality (Table 3). Table 4 showed via VARK inventory, the kinesthetic modality as preferred mode (male (53.84\%), and female $(50.35 \%)$ followed by the auditory style of preference.

Table 5 showing the modes of learning style preferred. Whether unimode, two, three and four modes of information. Few students preferred bimodal, which is the highest [(54 males (51.92\%), and 58 females (41.72\%)].

Other students preferred trimodal, [14 males (13.46\%), and 46 females (33.09\%)], and still few students preferred quadrimodal, [7 males (6.73\%), and 24 females (17.26\%)].

Regarding the male/female student's inclination for learning by a single, bimodal, trimodal, and quadric sensory inputs was the most for the bimodal inputs. The female students had a strong preference for the trimodal and the quadric modal modalities which is easily correlating with their style of being elaborative and descriptive in their pattern of learning while the male students had a preference for the unimodal as the next choice which again is identifiable with their style of being precise to the point understanding. Assessment of learning styles references among first-year medical students showed that only $27.88 \%$ of the male students preferred a single mode of information presentation in contrast to female students who had multimodal learning preferences. But both the male [54 (51.92)] and female [58 (41.72)] students had the bimodal preference for learning.

\section{LIMITATIONS}

- Noninclusion of the nursing students as this year the subject of physiology was to be taught by their faculty.

- Difficulty in convincing the students at times for completion of the form.

\section{REFLECTIONS}

- What was good: The project gives an insight to the instructor to develop their own methods for teaching and learning other then the routine didactic lectures in the interest of the students learners.

- What could have been differently: This study could have evaluated by taking lectures based totally on each of the modality and one lecture having all the modalities . the feedback would be taken from the students regarding the various lectures on the modalities.

- The road ahead: The teaching and learning method, when incorporated with the help of the preferred learning modalities of the students (male and female), it would be easier for the educators to pass the study material to their students in desired format and the learners will be able to imbibe it very effectively and, thus achieve higher academic excellence. 


\section{CONCLUSION}

Thus, the present study suggests that courses that utilize manipulation, interaction, and active learning may have a greater likelihood of benefiting learners who experience academic challenge. Kinesthetic was the preferred learning style by both, Individual preferred sensory modality and VARK inventory tool, and was found to be statistically significant among the students of medical and allied sciences. The gender differences when evaluated for both the Individual Preferred Sensory Modality and VARK inventory tool, it was found to have a predilection for the kinesthetic mode in both the male as well as female students. Understanding the number of modalities preferred by the male and female students, it was found the bimodal mode of learning to be the most common. It was followed by a slight preponderance for the multimodal method in the female students and unimodal in the male students.

\section{IMPLICATIONS}

The learning style can be evaluated for the students in all semesters, the educators could then instruct the students in their preferred mode of learning and thus help them to achieve their academic excellence.

\section{ACKNOWLEDGMENTS}

Corresponding author would like to thank all the students for participating in the project with full sincerity, MEU colleagues, and her department faculty, for helping her to complete the work in stipulated time. Last but not the least she thanks her family members for their constant support throughout the last 6 months.

\section{REFERENCES}

1. MuralidharaDV, NordinS, MohmadN. Learning style preferences of preclinical medical students in a Malaysian University. South East Asian Journal of Medical Education, 2013; 7(1):22-30.

2. Cooper SS. Life Circles, Inc. Learning Styles (online). http:// www.lifecircles-inc.com/learningstyles.htm [2007].

3. Heidi LL and Stephen ED. First year medical students prefer multiple learning styles. Adv Physiol Educ 2006;30:13-16.

4. James W, Gardner D. Learning styles: implications for distance learning. New Dir Adult Contin Educ 1995;67:19-32.

5. Fleming ND. I'm different, not dumb. Modes of presentation (VARK) in the tertiary classroom. In: Research and Development in Higher Education, edited by Zelmer A. Proceedings of the 1995 Annual Conference of the Higher Education and Research Development Society of Australasia 1995;18:308-313.

6. Johnson M. Evaluation of learning style for first year medical students. International Journal for the scholarship of teaching and learning. 2009;3(1):1-15.

7. Dobson JL. A comparison between learning style preferences and sex, status, and course performance. Adv Physiol Educ 2010;34:197-204.

8. Wehrwein EA, Lujan HL, DiCarlo SE. Gender differences in learning style preferences among undergraduate physiology students. Adv Physiol Educ 2007;31:153-157.

9. Lie LY, Angelique L, Cheong E. How do male and female students approach learning at NUS? CDTLbrief 2004;7:1-3.

10. Fleming ND. VARK: A Guide to Learning Styles (online) http://www.vark-learn.com/english/p_questionnaire [2007].

11. Kumar L, Voralu K, Pani S, Sethuraman K. Predominant learning styles adopted by AIMST university students in Malaysia. South East Asian Journal of Medical Education 2009;3:37-46.

12. Jindal M, Kharb P, Samanta PP. Comparative analysis of instructional learning preferences of Medical students of first and seventh semester. International Journal of Physiology 2013;1(1):32-36.

13. Prabha V. Learning styles among the first year dental students. International Journal of Health Sciences \& Research 2013;3:22-28. 